\title{
Salt effect on the enthalpy of mixing of 2-propanol + acetic acid at $303.15 \mathrm{~K}$
}

\author{
R. Tamilarasan', Sunil G. Baffna ${ }^{2}$, A. Anand-Prabu ${ }^{3}$, M. Dharmendira-Kumar ${ }^{2 *}$ \\ ${ }^{1}$ Department of Chemistry, Anna University, Tiruchirappalli - Pattukkottai Campus 614 701, India, \\ ${ }^{2}$ Department of Chemical Engineering, Alagappa College of Technology, Anna University, Chennai 600 025, India. \\ ${ }^{3}$ Department of Chemistry, School of Science, Vellore Institute of Technology University, Vellore 632 014, India \\ *Corresponding author: email: mdkumar@annauniv.edu
}

\begin{abstract}
This paper presents the effect of two dissolved inorganic salts (zinc chloride, $\mathrm{ZnCl}_{2}$ and ammonium chloride, $\mathrm{NH}_{4} \mathrm{Cl}$ ) on the enthalpy of mixing $\left(H^{\mathrm{E}}\right)$ of 2-propanol + acetic acid binary system measured at $303.15 \mathrm{~K}$ using an isothermal displacement calorimeter with vapour space. A decreasing trend in the excess enthalpy of mixing values in the presence of $\mathrm{ZnCl}_{2}$ and $\mathrm{NH}_{4} \mathrm{Cl}$ indicate the endothermic behavior of this system. The Redlich-Kister equation has been used to fit the experimental $H^{\mathrm{E}}$ data. The deviations from the ideal value and binary parameters were calculated and reported.
\end{abstract}

Keywords: Excess enthalpy, binary system, salt effect, 2-propanal, acetic acid.

\section{INTRODUCTION}

The excess thermodynamic properties of binary liquid mixtures are important to understand and interpret the nature of interactions between the molecules of the mixtures. Excess thermodynamic functions have been used as a qualitative guide to predict the extent of complex formation in binary liquid mixtures. Furter and $\operatorname{Cook}^{1}$ and Jacques and Furter ${ }^{2}$ have studied the influence of the added salt on the relative volatilities of two liquid components using 19 inorganic salts. The formation of the associated complexes or clusters of molecules of the volatile component around salt ions and its effect on relative volatilities have been studied extensively by Long and Mc Devit $^{3}$. The salt effect is also believed to be a complex function of salt + solvent interaction and self-interaction among the system components ${ }^{4}$. As the equation derived by Sada et al. ${ }^{5}$ indicated the changes in the chemical potential of the solvent components when a salt is added to a solvent mixture.

Properties like relative volatility and azeotrope are influenced by the addition of salts. Meranda and Furter ${ }^{6}$ have observed the gradual shift in the azeotropic composition in certain azeotropic systems by the addition of salts. Certain salts have been found to completely eliminate the azeotrope. Therefore, it is of greater interest to investigate the effect of dissolved salts on the enthalpy of mixing of liquid mixtures which are of commercial importance. Since there is an interrelation between the excess free energy and the excess enthalpy of liquid mixtures, a few researchers ${ }^{7,8}$ have studied the effect of added salts on the excess enthalpy values of liquid mixtures along with notable contributions from our group ${ }^{\mathbf{- 1 6}}$. In this investigation, the effect of two dissolved inorganic salts, namely zinc chloride and ammonium chloride on the enthalpy of mixing values of 2-propanol + acetic acid binary system has been studied experimentally.

\section{EXPERIMENTAL SECTION}

Analytical reagent grade 2-propanol, acetic acid, and the salts (zinc chloride and ammonium chloride) used in this investigation were supplied by E-Merck. The solvents were purified by fractional distillation; the physical properties of the solvents (density, $\rho$; boiling point, $T_{\mathrm{b}}$ ) and the salts (melting point, $T_{\mathrm{m}}$ ) used in this study were found to be almost identical to the literature values 17 as shown in Table 1. Their densities were measured using a bicapillary pycnometer and their boiling points were measured using an ebulliometer giving a precision of $\pm 0.2 \mathrm{~K}$. The salts were dried before use, and their melting point and purity (\%) values were received from the supplier.

Table 1. The physical properties of the solvents and salts used

\begin{tabular}{|l|c|c|}
\hline \multirow{2}{*}{ solvent } & this work & Ref. 17 \\
\cline { 2 - 3 } & \multicolumn{2}{|c|}{ boiling point, $T_{\mathrm{b}} /[\mathrm{K}]$} \\
\hline 2-propanol & 355.2 & 355.3 \\
\hline acetic acid & 390.6 & 390.9 \\
\hline \multirow{2}{*}{ 2-propanol } & \multicolumn{2}{|c|}{ density, $\rho /\left[\mathrm{g}^{\circ} \mathrm{cm}^{-3}\right]$ at $298.15 \mathrm{~K}$} \\
\hline acetic acid & 1.8010 & 1.8030 \\
\hline \multirow{2}{*}{ salt } & 1.0491 & 1.0492 \\
\hline zinc chloride & \multicolumn{2}{|c|}{ (as reported by the supplier) } \\
\cline { 2 - 3 } ammonium chloride & melting point, $T_{\mathrm{m}} / \mathrm{K}$ & purity \\
\hline \multirow{2}{*}{} & 566.35 & $\geq 99.9 \%$ \\
\hline
\end{tabular}

Preparation of the salt solutions, experimental procedures and the apparatus set-up adopted in this work has been reported in our previous paper ${ }^{15,16}$ and elaborated briefly in this section. The concentrations of the salts reported in this work [ $(5$ and 10$) \%]$ are the initial concentrations by mass [mass of salt/(mass of salt + mass of solvent)] before mixing with the other solvent. The performance of the calorimeter and its reliability for the measurement of the enthalpy of mixing values were ascertained by determining the enthalpy of mixing values of the non-salt water + methanol binary system at $303.15 \mathrm{~K}$ (Figure 1), and the data compared well (within 2\%) with the literature data ${ }^{18}$. Triplicate samples were prepared for each 2-propanol + acetic acid composition (refer to the varying mole $\%$ of 2-propanol $\left(x_{1}\right)$ values given in Tables 2 and 3 ) to ensure reproducibility (within $\pm 3 \%$ ), and the average values are presented. The mole fraction of acetic acid can be referred to as $x_{2}$ whereas $x_{3}$ refers to the mole fraction of solute (in Tables 2 and 3 ), and the sum of $x_{1}+x_{2}+x_{3}$ is equal to one. 
Table 2. Enthalpy of mixing the data for the system 2-propanol + acetic acid at $303.15 \mathrm{~K}$ for the salt $\mathrm{ZnCl}_{2}$

\begin{tabular}{|c|c|c|c|c|c|c|}
\hline \multicolumn{3}{|c|}{ no salt } & \multicolumn{4}{|c|}{$5 \% \mathrm{ZnCl}_{2}$} \\
\hline$x_{1}[\mathrm{~mol} \%]$ & $\begin{array}{c}H_{\text {exptl }}^{E} \\
{\left[\mathrm{~J} \cdot \mathrm{mol}^{-1}\right]}\end{array}$ & $\begin{array}{c}H^{\mathrm{E}} \text { calcd } \\
{\left[\mathrm{J} \cdot \mathrm{mol}^{-1}\right]}\end{array}$ & $\begin{array}{c}x_{1} \\
{[\mathrm{~mol} \%]}\end{array}$ & $\begin{array}{c}x_{3} \\
{[\mathrm{~mol} \%]}\end{array}$ & $\begin{array}{c}H^{E}{ }_{\text {exptt }} \\
{\left[\mathrm{J} \cdot \mathrm{mol}^{-1}\right]}\end{array}$ & $\begin{array}{c}H_{\text {calcd }}^{\mathrm{E}} \\
{\left[\mathrm{J} \cdot \mathrm{mol}^{-1}\right]}\end{array}$ \\
\hline 0.122 & 149.0 & 142.8 & 0.097 & $7.43 \times 10^{-2}$ & 589.6 & 590.2 \\
\hline 0.205 & 426.5 & 420.8 & 0.15 & $6.41 \times 10^{-2}$ & 836.1 & 841.2 \\
\hline 0.286 & 747.0 & 758.2 & 0.229 & $5.72 \times 10^{-2}$ & 1040.7 & 1032.1 \\
\hline 0.391 & 1177 & 1204 & 0.299 & $3.98 \times 10^{-2}$ & 1210.1 & 1201.5 \\
\hline 0.446 & 1440 & 1410.4 & 0.405 & $3.09 \times 10^{-2}$ & 1360.5 & 1295.2 \\
\hline 0.582 & 1760 & 1746.5 & 0.409 & $1.92 \times 10^{-2}$ & 1490.2 & 1482.1 \\
\hline 0.684 & 1751 & 1764.2 & 0.650 & $1.23 \times 10^{-2}$ & 1569.9 & 1574.2 \\
\hline 0.798 & 1472 & 1483.4 & 0.799 & $4.18 \times 10^{-3}$ & 1479.1 & 1581.2 \\
\hline 0.912 & 890.0 & 805.8 & 0.896 & $1.32 \times 10^{-3}$ & 1068.5 & 1062.1 \\
\hline
\end{tabular}

Table 3. Enthalpy of mixing the data for the system 2-propanol + acetic acid at $303.15 \mathrm{~K}$ for the $\mathrm{salt}_{\mathrm{ZnCl}}$ and $\mathrm{NH}_{4} \mathrm{Cl}$

\begin{tabular}{|c|c|c|c|c|c|c|c|}
\hline \multicolumn{4}{|c|}{$10 \% \mathrm{ZnCl}_{2}$} & \multicolumn{4}{|c|}{$5 \% \mathrm{NH}_{4} \mathrm{Cl}$} \\
\hline $\begin{array}{c}x_{1} \\
{[\mathrm{~mol} \%]}\end{array}$ & $\begin{array}{c}x_{3} \\
{[\mathrm{~mol} \%]}\end{array}$ & $\begin{array}{c}H_{\text {exptl }}^{\mathrm{E}} \\
{\left[\mathrm{J} \cdot \mathrm{mol}^{-1}\right]}\end{array}$ & $\begin{array}{c}H^{E} \text { calcd } \\
{\left[\mathrm{J} \cdot \mathrm{mol}^{-1}\right]}\end{array}$ & $\begin{array}{c}x_{1} \\
{[\mathrm{~mol} \%]}\end{array}$ & $\begin{array}{c}x_{3} \\
{[\mathrm{~mol} \%]}\end{array}$ & $\begin{array}{c}H^{\mathrm{E}} \text { exptl }^{-1} \\
{\left[\mathrm{~J} \cdot \mathrm{mol}^{-1}\right]}\end{array}$ & $\begin{array}{c}H_{\text {calcd }}^{E} \\
{\left[\mathrm{~J} \cdot \mathrm{mol}^{-1}\right]}\end{array}$ \\
\hline 0.130 & $7.66 \times 10^{-2}$ & 981.2 & 988.3 & 0.121 & $3.92 \times 10^{-2}$ & 189.6 & 193.3 \\
\hline 0.189 & $6.51 \times 10^{-2}$ & 1213.2 & 1199.3 & 0.201 & $2.92 \times 10^{-2}$ & 567.1 & 551.4 \\
\hline 0.287 & $5.16 \times 10^{-2}$ & 1411.2 & 1415.6 & 0.289 & $2.15 \times 10^{-2}$ & 898.6 & 912.9 \\
\hline 0.376 & $4.00 \times 10^{-2}$ & 1550.1 & 1550.3 & 0.395 & $1.59 \times 10^{-2}$ & 1165.9 & 1168.8 \\
\hline 0.44 & $3.10 \times 10^{-2}$ & 1610.1 & 1625.5 & 0.450 & $1.21 \times 10^{-2}$ & 1214.6 & 1215.3 \\
\hline 0.579 & $1.96 \times 10^{-2}$ & 1700.2 & 1678.9 & 0.582 & $6.98 \times 10^{-3}$ & 1168.9 & 1155.3 \\
\hline 0.682 & $1.19 \times 10^{-2}$ & 1590.2 & 1540.4 & 0.681 & $4.62 \times 10^{-3}$ & 1043.7 & 1039.3 \\
\hline 0.782 & $6.20 \times 10^{-3}$ & 1161.2 & 1203.3 & 0.796 & $2.71 \times 10^{-3}$ & 859.3 & 884.6 \\
\hline 0.910 & $1.71 \times 10^{-3}$ & 536.5 & 515.0 & 0.913 & $1.27 \times 10^{-3}$ & 598.6 & 579.0 \\
\hline 0.972 & $1.33 \times 10^{-4}$ & 150.2 & 149.8 & 0.972 & $6.27 \times 10^{-5}$ & 242.6 & 240.1 \\
\hline
\end{tabular}

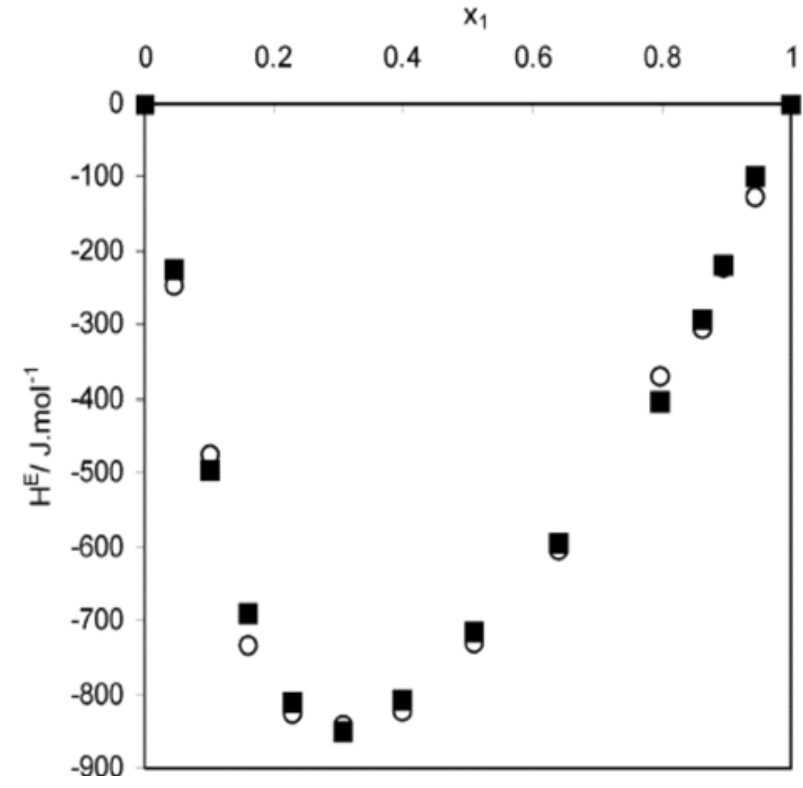

Figure 1. Enthalpy of mixing of water + methanol at 303.15 $\mathrm{K}$ : O, this work; $\mathbf{m}$, Battler and Rowley ${ }^{18}$

\section{RESULTS AND DISCUSSION}

The experimental excess enthalpy data obtained for the 2-propanol + acetic acid system under various salt conditions are given in the Tables 2 and 3 and also represented graphically in Figures 2 and 3. Both 2-propanol and acetic acid are polar protic solvents. The salts chosen in this study are $\mathrm{ZnCl}_{2}$ (5 and $10 \mathrm{wt} \%$ ) and $\mathrm{NH}_{4} \mathrm{Cl}$ (5 wt \%). Acetic acid possesses more solvating power than 2-propanol, and the salts are more freely soluble in acetic acid than in 2-propanol. The enthalpy of mixing of the salt-free system is endothermic. This is quite obvious from the fact that, within acetic acid, there are strong

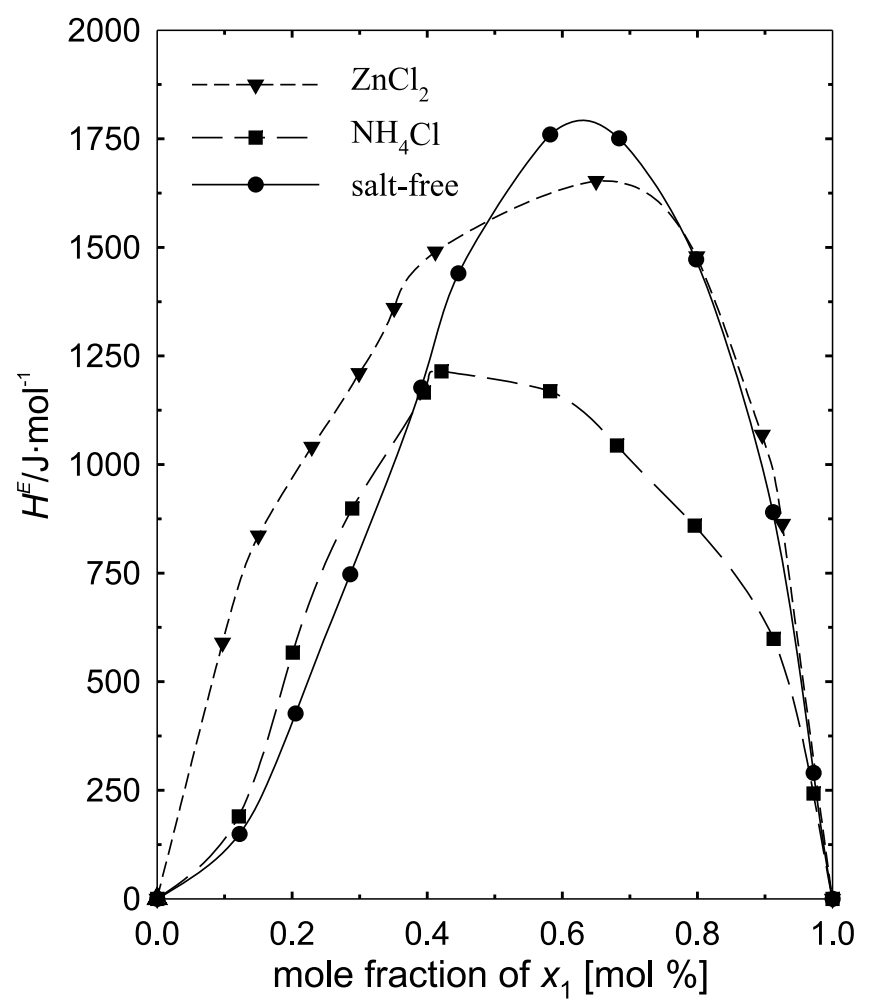

Figure 2. Effect of addition of $5 \%$ mass of salts, $\mathrm{ZnCl}_{2}(\boldsymbol{\nabla})$; $\mathrm{NH}_{4} \mathrm{Cl}(\boldsymbol{\bullet})$ and salt-free solution $(\bullet)$ on the enthalpy of mixing $\left(H^{\mathrm{E}}\right)$ of 2-propanol + acetic acid at $303.15 \mathrm{~K}$ against the mole fraction of $\mathrm{x}_{1}$. Solid lines and symbols indicate the calculated and experimental $H^{\mathrm{E}}$ values, respectively

intermolecular forces due to hydrogen bonding. The presence of carboxyl group assists intermolecular binding through both carboxyl and $\mathrm{OH}$ groups. In comparison, 2- 


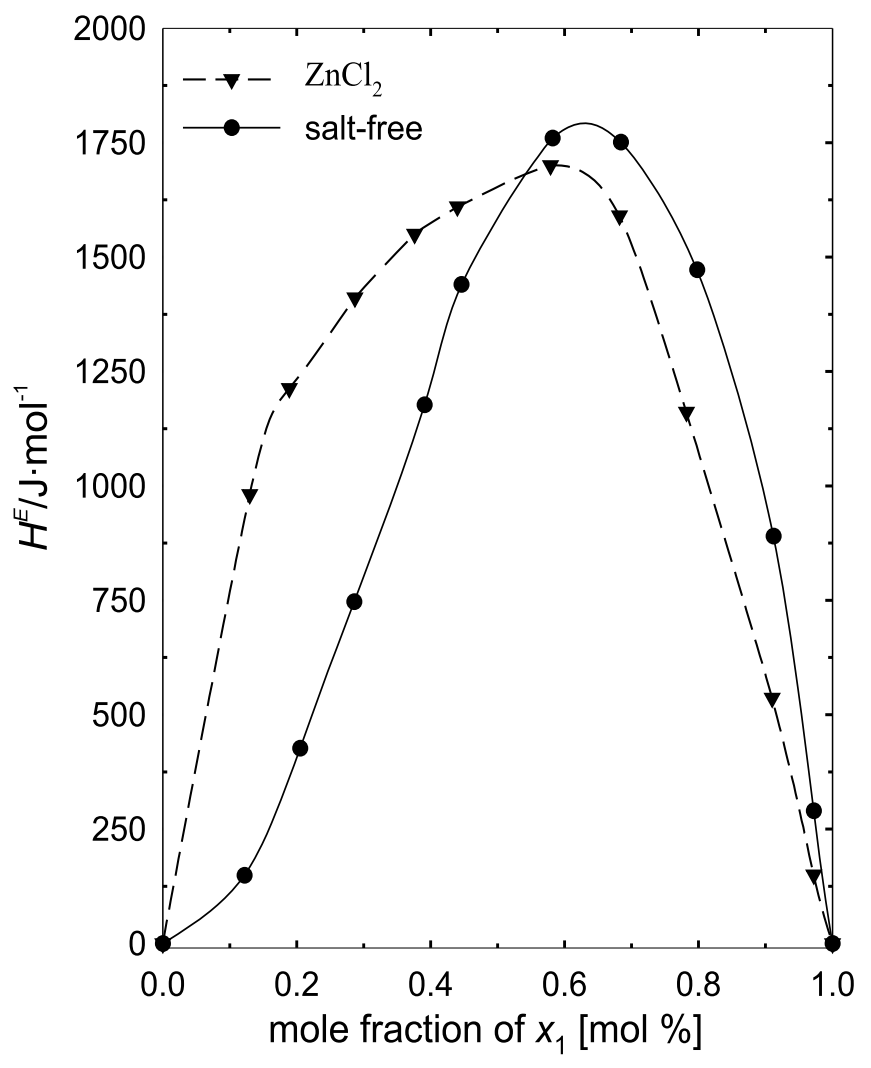

Figure 3. The effect of an addition of $10 \%$ mass of the salt $\mathrm{ZnCl}_{2}(\boldsymbol{\nabla})$ and salt-free solution $(\bullet)$ on the enthalpy of mixing $\left(H^{\mathrm{E}}\right)$ of 2-propanol + acetic acid at 303.15 $\mathrm{K}$ against the mole fraction of $\mathrm{x}_{1}$. The solid lines and symbols indicate the calculated and experimental $H^{\mathrm{E}}$ values, respectively

propanol is weakly associated. Although alcoholic $\mathrm{OH}$ aids intermolecular association through hydrogen bonding, the large alkyl group disfavors enhanced molecular association. Hence, the weakly associated 2-propanol in the presence of the strongly associated acetic acid exhibits endothermic excess enthalpy values.

The influence of the added salts on the separation feasibility of 2-propanol + acetic acid system is evaluated from Figures 2 and 3. The salts used in the present study differently alter the magnitude of endothermic excess enthalpy in the region of low and high mole fraction of 2propanol (referred to as $x_{1}$ in Figures 2 and 3). In the region of lower mole fraction of 2-propanol, an increase in the $H^{\mathrm{E}}$ values with the added salts was observed and the reverse trend was observed in the region of high mole fraction. Hence, the phase separation in 2-propanol + acetic acid system is expected to be difficult even in the presence of salts if the mole fraction of 2-propanol is less. On the other hand, phase separation becomes easier with higher mole fraction of 2-propanol. During the actual process of separation of two components by distillation, it would be more beneficial if the mole fraction of 2- propanol in the pot residue is maintained at around 0.5 in the presence of any of the chosen salts. Among the salts examined, $\mathrm{NH}_{4} \mathrm{Cl}$ largely favor phase separation compared to $\mathrm{ZnCl}_{2}$. The influence of the salts $\mathrm{ZnCl}_{2}$ and $\mathrm{NH}_{4} \mathrm{Cl}$ on the excess enthalpy of mixing of this system under different salt concentration is illustrated in the Tables 2 and 3.

\section{Data Correlation and Statistical Analysis}

The Redlich-Kister model expresses the excess free energy of mixing as the sum of terms which consists of a function of the mole fractions of each component and an interaction parameter. In this study, the effect of added salts on the experimental enthalpy data $\left(H^{\mathrm{E}}\right)$ was correlated with $H^{\mathrm{E}}$ values calculated using the Redlich-Kister polynomial $^{19}$.

$H^{E} /\left[\mathrm{J} \cdot \mathrm{mol}^{-1}\right]=x_{1} x_{2} \sum_{i=0}^{j} A_{i}\left(2 x_{1}-1\right)^{i}$

where $H^{\mathrm{E}}$ is the enthalpy of mixing; $x_{1}$ and $x_{2}$ are the mole fractions of the solvents 1 and 2, respectively; and $A_{\mathrm{i}}$ is $a$ constant that is a function of temperature and the system properties.

The experimental $H^{\mathrm{E}}$ values were fitted with Eq. (1) by the least-squares method with each point weighted equally, and the binary parameters $\left(A_{\mathrm{i}}\right)$ were evaluated. The modeling results are listed in Table 4 along with the percentage standard deviation $\left(\% \sigma\left(H^{\mathrm{E}}\right)\right)$. The values of the percentage standard deviation $\sigma$ are computed from Eq. (2) and shown in Table 4.

$$
\% \sigma\left(H^{\mathrm{E}}\right)=\left[\frac{\sum\left(\frac{H^{\mathrm{E}} \exp t l-H^{\mathrm{E}} \text { calcd }}{H^{E}} \cdot 100\right)^{2}}{(N-K)}\right]^{1 / 2}
$$

where $N$ and $K$ are the number of data points and the number of parameters, respectively. The results obtained showed that the amount of the added salt has a strong effect on the estimated parameters and their corresponding standard deviations, which may have ensued from the interaction between the individual salt and the functional groups present in 2-propanol + acetic acid system.

\section{CONCLUSION}

From the experimental $H^{\mathrm{E}}$ and statistical data obtained in the present study using 2-propanol + acetic acid system, the salt $\mathrm{NH}_{4} \mathrm{Cl}$ largely favored phase separation compared to $\mathrm{ZnCl}_{2}$ by influencing the interaction between the weakly associated alcohol and the strongly associated acetic acid resulting in endothermic excess enthalpy values. The model represented the experimental data with the required

Table 4. The estimated parameters of equation (1) and the percentage of standard deviation $\% \sigma\left(H^{\mathrm{E}}\right)$ of the system 2-propanol + acetic acid at $303.15 \mathrm{~K}$

\begin{tabular}{|l|c|c|c|c|c|}
\hline Salt conc. [wt.\%] & $A_{0}$ & $A_{1}$ & $A_{2}$ & $A_{3}$ & $\% \sigma\left(H^{\mathrm{E}}\right)$ \\
\hline no salt & 6315.54 & 5478.73 & -1323.18 & 194.59 & 1.96 \\
\hline $5 \% \mathrm{ZnCl} 2$ & 5888.08 & 2016.96 & 5088.93 & 1656.00 & 1.44 \\
\hline $10 \% \mathrm{ZnCl}_{2}$ & 6691.18 & 1068.62 & 1821.48 & -4541.17 & 1.68 \\
\hline $5 \% \mathrm{NH}_{4} \mathrm{Cl}$ & 4860.99 & -675.59 & -1132.29 & 6670.05 & 1.89 \\
\hline
\end{tabular}


accuracy for the studied system and therefore, this model is suitable to predict the excess enthalpy of mixing in 2propanol + acetic acid binary mixture in the presence of the selected inorganic salts.

\section{LITERATURE CITED}

1. Furter, W.F. \& Cook, R.A. (1967). Salt effect in distillation: A literature review. Int. J. Heat Mass Tran. 10(1), 23 - 36. DOI: 10.1016/0017-9310(67)90181-0.

2. Jacques, D. \& Furter, W.F. (1972). Salt effect in vapour liquid equilibrium: Testing the thermodynamic consistency of ethanol-water saturated with inorganic salts. AIChE J. 18(2), 343 - 346. DOI: 10.1002/aic.690180216.

3. Long, F.A. \& McDevit, W.F. (1952). Activity coefficients of nonelectrolytes solutes in aqueous salt solutions. Chem. Rev. 51(1), 119 - 169. DOI: 10.1021/cr60158a004.

4. Furter, W.F. (1976). Correlation and prediction of salt effect in vapor-liquid equilibrium. In W. F. Furter, Thermodynamic behavior of electrolytes in mixed solvents (pp. 26 - 39), Advances in chemistry series 155 . American Chemical Society, Washington DC. DOI: 10.1021/ba-1976-0155.ch003.

5. Sada, E., Morisue, T. \& Miyahara, K. (1975). Salt effect in vapour liquid equilibrium of tetra hydrofuran-water system. J. Chem. Eng. Data. 20(3), 283 - 287. DOI: 10.1021/ je60066a016.

6. Meranda, D. \& Furter, W.F. (1974). Salt effect on vapour liquid equilibrium: some anomalies. AIChE J. 20(1), 103 - 108. DOI: 10.1002/aic.690200113.

7. Nowicka, B., Osinska, S.T. \& Gatta, G.D. (1997). Enthalpies of solution of $\mathrm{N}$-acetylamino acid amides in aqueous solutions of electrolytes at the temperature $298.15 \mathrm{~K}$. $J$. Chem. Thermodyn. 29(9), 1017 - 1024. DOI: 10.1006/ jcht.1997.0218.

8. Zhang, R., Yan, W., Wang, X. \& Lin, R. (2005). Molar excess enthalpies of ethyl acetate + alkanols at $\mathrm{T}=298.15 \mathrm{~K}$, $\mathrm{p}=10.0 \mathrm{MPa}$. Thermochim. Acta. 429(2), 155 - 161. DOI: 10.1016/j.tca.2005.03.009.

9. Rajendran, M., Renganarayanan, S., Madhavan, P.R. \& Srinivasan, D. (1988). Effect of dissolved inorganic salts on vapour liquid equilibria and heat of mixing of methanol ethyl acetate system. Chem. Eng. Commun. 74(1), 179 - 193. DOI: $10.1080 / 00986448808940458$.

10. Rajendran, M., Renganarayanan, S., Madhavan, P.R. \& Srinivasan, D. (1989). Effect of dissolved salts on heat of mixing of three miscible binary system. J. Chem. Eng. Data. 34(4), 375 - 382. DOI: 10.1021/je00058a002.

11. Rajendran, M., Renganarayanan, S. \& Srinivasan, D. (1991). Salt effect in phase equilibria and heat of mixing: effect of dissolved inorganic salts on the liquid-liquid equilibria of ethyl acetate - 2-propanol - water system and the vapour liquid equilibria and heat of mixing of its constituent binaries. Fluid phase Equilib. 70(1), 65 - 106. DOI: 10.1016/03783812(91)85005-F.

12. Rajendran, M. \& Srinivasan, D. (1994). Salt effect in heat of mixing: effect of dissolved salts on enthalpy of mixing of 2-propanol-benzene system. Chem. Eng. Commun. 128(1), 109 - 117. DOI: 10.1080/00986449408936238.

13. Kumar, M. D. \& Rajendran, M. (1999). Salt effect on enthalpy of mixing of water + methanol at 303.15 K. Fluid Phase Equilib. 164(2), 217 - 224. DOI: 10.1016/S03783812(99)00233-2.

14. Tamilarasan, R., Prabu, A.A, Kumar, M.D. \& Yoo, C.K. (2008). Salt effect on the enthalpy of mixing of 1,4-dioxane + formic acid at 303.15 K. J. Chem. Eng. Data. 53(4), 966 969. DOI: $10.1021 / \mathrm{je} 7007022$.

15. Tamilarasan, R., Prabu, A.A., Raajenthiren, M., Kumar, M.D. \& Yoo, C.K. (2009). Effect of dissolved salts on the enthalpy of mixing of methanol + formic acid system at
303.15 K. J. Chem. Eng. Data. 54(1), 4 - 7. DOI: 10.1021/ je $800568 \mathrm{~m}$.

16. Tamilarasan, R., Prabu, A.A., Raajenthiren, M., Kumar, M.D. \& Yoo, C.K. (2009). J. Chem. Eng. Jpn. 42(7), 485 - 489. DOI: $10.1252 /$ jcej.09we053.

17. Timmermanns, J. (1959). The Physico-chemical constants of binary systems in concentrated solutions. New York, U.S.A.: Wiley-Interscience Publishers.

18. Battler, J.R. \& Rowley, R.L. (1985). Excess enthalpies between $293 \mathrm{~K}$ and $323 \mathrm{~K}$ for constituent binaries of ternary mixtures exhibiting partial miscibility. J. Chem. Thermodyn. 17(8), 719 - 732. DOI: 10.1016/0021-9614(85)90101-6.

19. Redlich, O.; Kister, A.T. (1948) Algebraic representation of thermodynamic properties and classification of solutions. Ind. Eng. Chem. 40, 345 - 348. 